\title{
Amplification by (-)-epigallocatechin gallate and chlorogenic acid of TNF- $\alpha$-stimulated interleukin-6 synthesis in osteoblasts
}

\author{
NAOHIRO YAMAMOTO ${ }^{1,2}$, HARUHIKO TOKUDA ${ }^{2,3}$, GEN KUROYANAGI $^{1,2}$, SHINGO KAINUMA $^{1,2}$, \\ REOU OHGUCHI ${ }^{1,2}$, KAZUHIKO FUJITA ${ }^{1,2}$, RIE MATSUSHIMA-NISHIWAKI ${ }^{2}$, \\ OSAMU KOZAWA $^{2}$ and TAKANOBU OTSUKA ${ }^{1}$ \\ ${ }^{1}$ Department of Orthopedic Surgery, Nagoya City University Graduate School of Medical Sciences, \\ Nagoya 467-8601; ${ }^{2}$ Department of Pharmacology, Gifu University Graduate School of Medicine, Gifu 501-1194; \\ ${ }^{3}$ Department of Clinical Laboratory, National Center for Geriatrics and Gerontology, Obu, Aichi 474-8511, Japan
}

Received July 13, 2015; Accepted October 14, 2015

DOI: 10.3892/ijmm.2015.2381

\begin{abstract}
Polyphenolic compounds in foods and beverages have beneficial effects on human health. (-)-Epigallocatechin gallate (EGCG) and chlorogenic acid (CGA), a major flavonoid in green tea and a major phenolic acid in coffee, respectively, have potent properties, including antioxidative effects. Our previous study demonstrated that p70 S6 kinase acts as a negative regulator in tumor necrosis factor- $\alpha$ (TNF- $\alpha$ )-stimulated interleukin- 6 synthesis in osteoblast-like MC3T3-E1 cells. In the present study, the effects of EGCG and CGA on the TNF- $\alpha$-stimulated interleukin-6 synthesis were investigated in MC3T3-E1 cells. EGCG and CGA significantly enhanced TNF- $\alpha$-stimulated interleukin- 6 release. In addition, the interleukin- 6 mRNA expression levels induced by TNF- $\alpha$ were supported by EGCG, as well as CGA.EGCG markedly attenuated the TNF- $\alpha$-induced phosphorylation of p70 S6 kinase whereas CGA failed to affect the phosphorylation. These results strongly suggest that EGCG and CGA enhance the TNF- $\alpha$-stimulated interleukin- 6 synthesis in osteoblasts, and that the amplifying effect of EGCG, but not CGA, is exerted via inhibiting p70 S6 kinase.
\end{abstract}

\section{Introduction}

Green tea and coffee are the most commonly consumed beverages worldwide. Green tea has been consumed mainly in Eastern countries, while coffee is consumed throughout the world. (-)-Epigallocatechin gallate (EGCG), the most abundant catechin and a major bioactive component in green tea, and chlorogenic acid (CGA), a main phenolic compound in coffee, have beneficial properties for human health, such as antioxidation, anti-inflammation and cancer prevention (1-3).

Correspondence to: Dr Haruhiko Tokuda, Department of Clinical Laboratory, National Center for Geriatrics and Gerontology, 7-430 Morioka-cho, Obu, Aichi 474-8511, Japan

E-mail: tokuda@ncgg.go.jp

Key words: (-)-epigallocatechin gallate, chlorogenic acid, tumor necrosis factor- $\alpha$, interleukin-6, p70 S6 kinase, osteoblast
Bone metabolism is regulated strictly by two types of functional cells, osteoblasts and osteoclasts, which are responsible for bone formation and resorption, respectively (4). Bone tissue in the skeleton is continuously renewed through a process, known as bone remodeling (5). A decrease in bone mineral density results from an unbalanced bone remodeling process (5). This remodeling process begins with osteoclast bone resorption, followed by osteoblast bone formation (6). Bone remodeling disorder causes metabolic bone disease, including osteoporosis, and the increased risk of fracture. It has been shown that ingestion of green tea prevents age-related bone loss and fractures in elderly individuals (7). Accumulating evidence indicates that catechin suppresses bone resorption and supports osteoblastic bone formation (7,8). Additionally, catechin stimulates alkaline phosphatase activity, a mature osteoblast phenotype, and reduces apoptosis in osteoblasts (7). By contrast, it has been shown that CGA increases mineralization in the tibia, and improves mechanical properties of the femoral diaphysis in rat model (9). In addition, CGA reportedly inhibits osteoclast differentiation and bone resorption by downregulation of receptor activator of nuclear factor $\kappa \mathrm{B}$ (RANK) ligand-induced nuclear factor of activated $\mathrm{T}$ cell $\mathrm{cl}$ expression (10). However, the exact mechanisms underlying the effects of EGCG or CGA on bone metabolism remain to be elucidated.

Tumor necrosis factor (TNF)- $\alpha$, a multifunctional cytokine, is firmly established to have an important role in inflammation, infection and cancer (11). With regard to bone metabolism, TNF- $\alpha$ stimulates the activation of RANK in osteoclasts through RANK ligand expression in osteoblasts, which acts as a potent stimulator of osteoclastogenesis (12). It has been reported that TNF- $\alpha$ stimulates the synthesis of interleukin-6 (13). Interleukin-6 is a member of the gp130 cytokine family and has important physiological effects on a wide range of functions, such as promotion of B-cell differentiation, T-cell activation and induction of acute-phase proteins $(11,14,15)$. As for the association between interleukin-6 and bone metabolism, it is well recognized that interleukin- 6 stimulates bone resorption and induces osteoclast formation $(11,14)$. By contrast, interleukin- 6 has a pivotal role in the process of bone fracture repair (16). Thus, interleukin-6 is currently considered to also be an osteotropic factor and influence bone 
formation under the condition of increased bone turnover (17). Our previous studies have shown that interleukin-6 synthesis induced by TNF- $\alpha$ is negatively regulated through the p70 S6 kinase pathway in osteoblast-like MC3T3-E1 cells $(18,19)$.

In the present study, the effects of EGCG or CGA on TNF- $\alpha$-induced interleukin- 6 synthesis in osteoblast-like MC3T3-E1 cells were investigated.

\section{Materials and methods}

Materials. EGCG and CGA were obtained from Sigma-Aldrich (St. Louis, MO, USA). TNF- $\alpha$ and mouse interleukin- 6 enzyme-linked immunosorbent assay (ELISA) kit were obtained from R\&D Systems, Inc. (Minneapolis, MN, USA). Phospho-specific p70 S6 kinase (Thr-389) antibodies (\#9205; polyclonal; rabbit anti-mouse; 1:1,000) and p70 S6 kinase antibodies (\#9202; polyclonal; rabbit anti-mouse; 1:1,000) were obtained from Cell Signaling Technology, Inc. (Beverly, MA, USA). An ECL western blotting detection system was obtained from GE Healthcare UK Ltd. (Buckinghamshire, UK). Other materials and chemicals were obtained from commercial sources. EGCG was dissolved in dimethyl sulfoxide and CGA was dissolved in ethanol. The maximum concentration of dimethyl sulfoxide or ethanol was $0.1 \%$, which did not affect the assay for interleukin- 6 or the western blot analysis.

Cell culture. Cloned osteoblast-like MC3T3-E1 cells derived from newborn mouse calvaria (20) were maintained as previously described (21). Briefly, the cells were cultured in $\alpha$-minimum essential medium ( $\alpha$-MEM) containing $10 \%$ fetal bovine serum (FBS) at $37^{\circ} \mathrm{C}$ in a humidified atmosphere of $5 \% \mathrm{CO}_{2} / 95 \%$ air. The cells were seeded in $35-\mathrm{mm}$ diameter dishes $\left(5 \times 10^{4}\right.$ cells/dish) or $90-\mathrm{mm}$ diameter dishes ( $2 \times 10^{5}$ cells/dish) in $\alpha$-MEM containing $10 \%$ FBS. After 5 days, the medium was exchanged for $\alpha$-MEM containing $0.3 \%$ FBS. The cells were used for experiments after $48 \mathrm{~h}$.

Assay for interleukin-6. The cultured cells were pretreated with various doses of EGCG or CGA for $60 \mathrm{~min}$, and subsequently stimulated by $30 \mathrm{ng} / \mathrm{ml}$ of TNF- $\alpha$ or vehicle in $1 \mathrm{ml}$ of $\alpha$-MEM containing $0.3 \%$ FBS for the indicated periods. The conditioned medium was collected at the end of the incubation, and the interleukin- 6 concentration was subsequently measured using mouse interleukin-6 ELISA kit according to the manufacturer's protocol.

Reverse transcription-quantitative polymerase chain reaction (RT-qPCR). The cultured cells were pretreated with $100 \mu \mathrm{M}$ of EGCG, $50 \mu \mathrm{M}$ of CGA or vehicle for $60 \mathrm{~min}$, and subsequently stimulated by $30 \mathrm{ng} / \mathrm{ml}$ of TNF- $\alpha$ or vehicle in $\alpha$-MEM containing $0.3 \%$ FBS for $3 \mathrm{~h}$. Total RNA was isolated and transcribed into complementary DNA using TRIzol reagent (Invitrogen Corp., Carlsbad, CA, USA) and Omniscript reverse transcriptase kit (Qiagen Inc., Valencia, CA, USA), respectively. RT-qPCR was performed using a LightCycler system in capillaries and Fast Start DNA Master SYBR-Green I provided with the kit (Roche Diagnostics, Basel, Switzerland). Sense and antisense primers for mouse interleukin-6 mRNA were purchased from Takara Bio Inc. (Tokyo, Japan) (primer set ID: MA039013), while mouse glyceraldehyde-3-phosphate dehydrogenase (GAPDH) mRNA primers were synthesized based on the study by Simpson et al (22). The amplified products were determined using melting curve analysis and agarose electrophoresis. The interleukin- 6 mRNA levels were normalized to those of GAPDH mRNA.

Western blot analysis. The cultured cells were pretreated with various doses of EGCG or CGA for $60 \mathrm{~min}$, and subsequently stimulated by $30 \mathrm{ng} / \mathrm{ml}$ of TNF- $\alpha$ or vehicle in $\alpha$-MEM containing $0.3 \% \mathrm{FBS}$ for $10 \mathrm{~min}$. The cells were washed twice with phosphate-buffered saline and lysed, homogenized and sonicated in a lysis buffer containing $62.5 \mathrm{mM}$ Tris/ $\mathrm{HCl}$ (pH 6.8) 2\% sodium dodecyl sulfate (SDS), $50 \mathrm{mM}$ dithiothreitol and $10 \%$ glycerol. SDS-polyacrylamide gel electrophoresis was performed by the method of Laemmli (23) in $10 \%$ polyacrylamide gels. The proteins were fractionated and transferred onto Immun-Blot polyvinyl difluoride (PVDF) membranes (Bio-Rad Laboratories, Hercules, CA, USA). The membranes were blocked with 5\% fat-free dry milk in Tris-buffered saline-Tween [TBS-T; $20 \mathrm{mM}$ Tris- $\mathrm{HCl}$ (pH 7.6), $137 \mathrm{mM} \mathrm{NaCl}$ and 0.1\% Tween-20] for $2 \mathrm{~h}$ before incubation with primary antibodies. A western blot analysis was performed as previously described (24) using phospho-specific p70 S6 kinase antibodies or p70 S6 kinase antibodies as primary antibodies, with peroxidase-labeled antibodies raised in goat against rabbit immunoglobulin $\mathrm{G}$ (no. 074-1506; KPL, Inc., Gaithersburg, MD, USA) used as the secondary antibodies. The primary and secondary antibodies were diluted at 1:1,000 with 5\% fat-free dry milk in TBS-T. The peroxidase activity on the PVDF sheet was visualized on X-ray film by means of the ECL Western blotting detection system.

Determination. The absorbance of the enzyme immunosorbent assay samples was measured at $450 \mathrm{~nm}$ with the EL 340 Bio Kinetic Reader (Bio-Tek Instruments, Inc., Winooski, VT, USA). A densitometric analysis was performed using a scanner and image analysis software package (ImageJ version 1.47; National Institutes of Health, Bethesda, MD, USA). The phosphorylated protein levels were calculated as follows: The background-subtracted signal intensity of each phosphorylation signal was respectively normalized to the total protein signal and plotted as the fold increase in comparison with that of the control cells treated without stimulation.

Statistical analysis. The data were analyzed by an analysis of variance followed by Bonferroni method for multiple comparisons between pairs, and $\mathrm{P}<0.05$ was considered to indicate a statistically significant difference. All the data are presented as the means \pm standard error of the mean of triplicate determinations from three independent cell preparations.

\section{Results}

Effect of EGCG on the TNF- $\alpha$-stimulated interleukin- 6 release in MC3T3-E1 cells. Our previous study showed that TNF- $\alpha$ stimulates interleukin-6 synthesis in osteoblast-like MC3T3-E1 cells (18). Firstly, the effect of EGCG on the TNF- $\alpha$-stimulated interleukin-6 release in MC3T3-E1 cells was examined. EGCG significantly amplified the TNF- $\alpha$-stimulated interleukin-6 release in a time-dependent manner $\leq 48 \mathrm{~h}$ (Fig. 1A). The enhancing effect of EGCG was dose-dependent between 10 

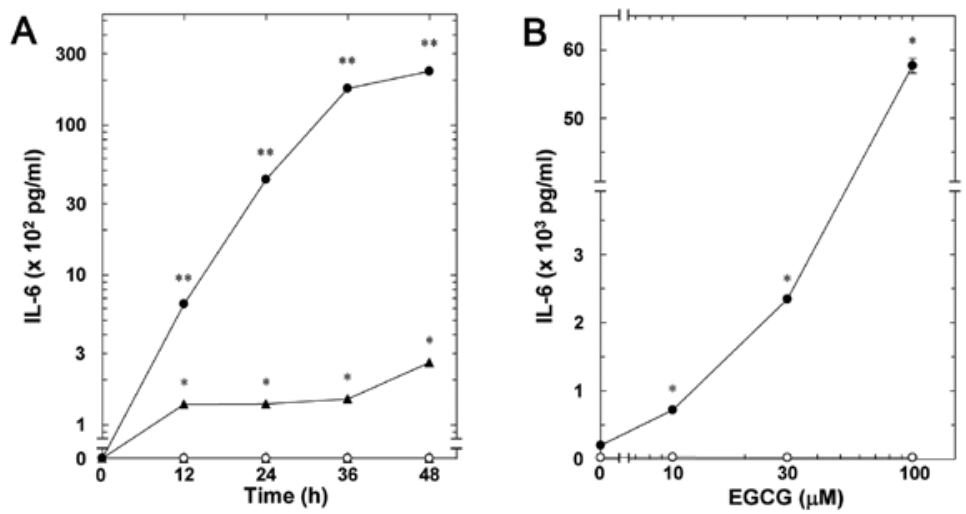

Figure 1. Effect of (-)-epigallocatechin gallate (EGCG) on the tumor necrosis factor- $\alpha$ (TNF- $\alpha$ )-stimulated interleukin-6 release in MC3T3-E1 cells. (A) The cultured cells were pretreated with $100 \mu \mathrm{M}$ of $\operatorname{EGCG}(\bullet, \circ)$ or vehicle $(\boldsymbol{\Lambda}, \Delta)$ for $60 \mathrm{~min}$, and subsequently stimulated by $30 \mathrm{ng} / \mathrm{ml}$ of TNF- $\alpha(\bullet, \mathbf{\Delta})$ or vehicle $(0, \Delta)$ for the indicated periods. " $\mathrm{P}<0.05$ compared to the value of the control; ${ }^{* *} \mathrm{P}<0.05$ compared to the value of TNF- $\alpha$ alone. (B) The cultured cells were pretreated with various doses of EGCG for $60 \mathrm{~min}$, and subsequently stimulated by $30 \mathrm{ng} / \mathrm{ml}$ of TNF- $\alpha(\bullet)$ or vehicle (o) for $48 \mathrm{~h}$. "P<0.05 compared to the value of TNF- $\alpha$ alone. The interleukin- 6 concentrations in the culture medium were determined using ELISA. Each value represents the mean \pm standard error of the mean of triplicate determinations from three independent cell preparations.
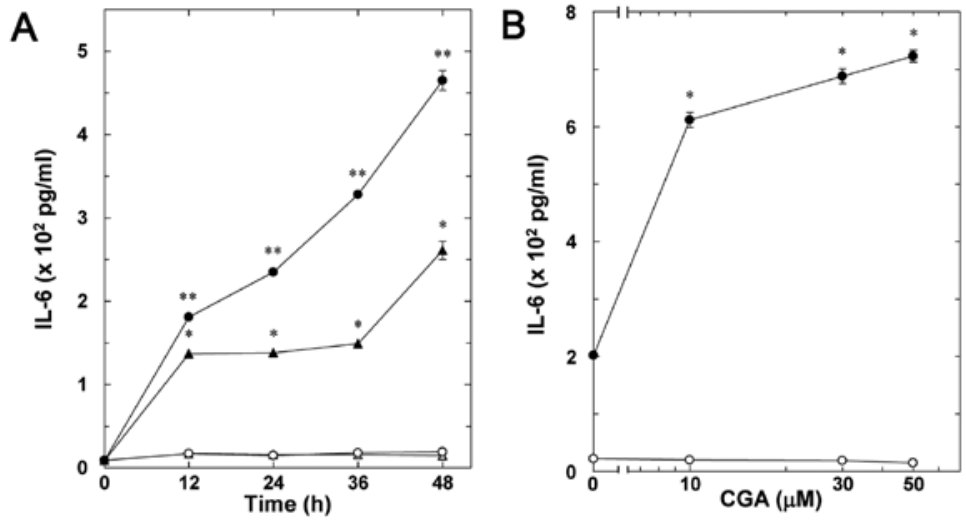

Figure 2. Effect of chlorogenic acid (CGA) on the tumor necrosis factor- $\alpha$ (TNF- $\alpha$ )-stimulated interleukin- 6 release in MC3T3-E1 cells. (A) The cultured cells were pretreated with $50 \mu \mathrm{M}$ of CGA $(\bullet, O)$ or vehicle $(\mathbf{\Lambda}, \Delta)$ for $60 \mathrm{~min}$, and subsequently stimulated by $30 \mathrm{ng} / \mathrm{ml}$ of TNF- $\alpha(\bullet, \mathbf{\Lambda})$ or vehicle $(O, \Delta)$ for the indicated periods. ${ }^{*} \mathrm{P}<0.05$ compared to the value of the control; ${ }^{* *} \mathrm{P}<0.05$ compared to the value of TNF- $\alpha$ alone. (B) The cultured cells were pretreated with various doses of CGA for $60 \mathrm{~min}$, and subsequently stimulated by $30 \mathrm{ng} / \mathrm{ml}$ of TNF- $\alpha(\bullet)$ or vehicle (O) for $48 \mathrm{~h}$. "P<0.05 compared to the value of TNF- $\alpha$ alone. The interleukin- 6 concentrations in the culture medium were determined using ELISA. Each value represents the mean \pm standard error of the mean of triplicate determinations from three independent cell preparations.

and $100 \mu \mathrm{M}$ (Fig. 1B). The maximum effect of EGCG on the interleukin-6 release was observed at $100 \mu \mathrm{M}$.

Effect ofCGA on the TNF- $\alpha$-stimulated interleukin-6 release in MC3T3-E1 cells. The effect of CGA on the TNF- $\alpha$-stimulated interleukin-6 release in osteoblast-like MC3T3-E1 cells was examined. CGA significantly enhanced the TNF- $\alpha$-stimulated interleukin- 6 release in a time-dependent manner $\leq 48 \mathrm{~h}$ (Fig. 2A). The enhancement by CGA on the release was dose-dependent between 10 and $50 \mu \mathrm{M}$ (Fig. 2B).

Effects of EGCG or CGA on the TNF- $\alpha$-induced expression of interleukin- 6 mRNA in MC3T3-El cells. In order to investigate whether the amplifying effect of EGCG or CGA on the TNF- $\alpha$-stimulated interleukin- 6 release is mediated via transcriptional events in MC3T3-E1 cells, the effects of EGCG or CGA on the TNF- $\alpha$-induced interleukin- 6 mRNA expression were examined. EGCG or CGA, which by itself had little effect on the interleukin- 6 mRNA levels, markedly upregulated the TNF- $\alpha$-induced interleukin-6 mRNA expression levels (Fig. 3).

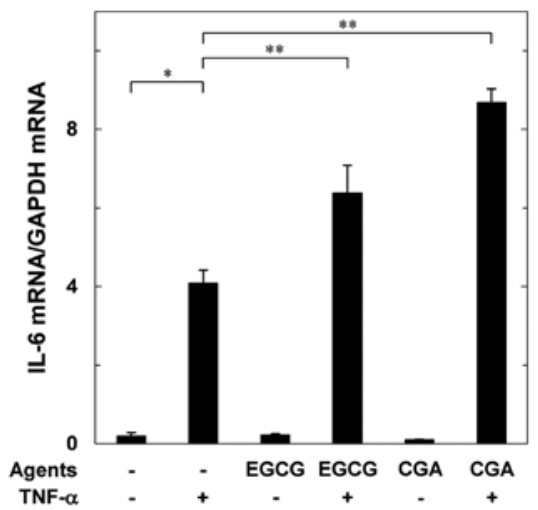

Figure 3. Effects of (-)-epigallocatechin gallate (EGCG) or chlorogenic acid (CGA) on the tumor necrosis factor- $\alpha$ (TNF- $\alpha$ )-induced expression levels of interleukin-6 mRNA in MC3T3-E1 cells. The cultured cells were pretreated with $100 \mu \mathrm{M}$ of EGCG, $50 \mu \mathrm{M}$ of CGA or vehicle for $60 \mathrm{~min}$, and subsequently stimulated by $30 \mathrm{ng} / \mathrm{ml}$ of TNF- $\alpha$ or vehicle for $3 \mathrm{~h}$. The respective total RNA was subsequently isolated and quantified using RT-qPCR. Each value represents the mean \pm standard error of the mean of triplicate determinations from three independent cell preparations. ${ }^{\text {}} \mathrm{P}<0.05$ compared to the value of the control; ** $\mathrm{P}<0.05$ compared to the value of TNF- $\alpha$ alone. 




Figure 4. Effect of (-)-epigallocatechin gallate (EGCG) on the tumor necrosis factor- $\alpha(\mathrm{TNF}-\alpha)$-induced phosphorylation of p70 S6 kinase in MC3T3-E1 cells. The cultured cells were pretreated with various doses of EGCG for $60 \mathrm{~min}$, and subsequently stimulated by $30 \mathrm{ng} / \mathrm{ml}$ of TNF- $\alpha$ or vehicle for $10 \mathrm{~min}$. The cell extracts were subsequently subjected to SDS-PAGE with subsequent western blot analysis with antibodies against phospho-specific p70 S6 kinase or p70 S6 kinase. The histogram shows quantitative representation of the levels of TNF- $\alpha$-induced phosphorylation obtained from a laser densitometric analysis of three independent experiments. Each value represents the mean \pm standard error of the mean of triplicate determinations. " $\mathrm{P}<0.05$ compared to the value of the control; ${ }^{* *} \mathrm{P}<0.05$ compared to the value of TNF- $\alpha$ alone.

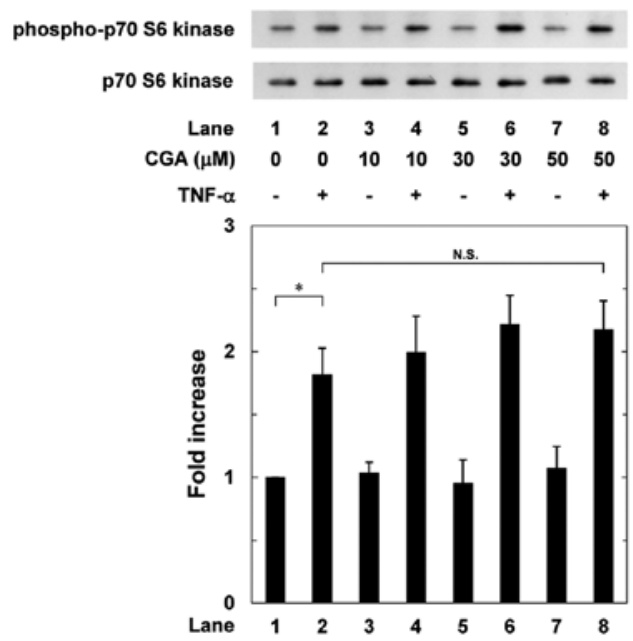

Figure 5. Effect of chlorogenic acid (CGA) on the tumor necrosis factor- $\alpha$ (TNF- $\alpha$ )-induced phosphorylation of p70 S6 kinase in MC3T3-E1 cells. The cultured cells were pretreated with various doses of CGA for $60 \mathrm{~min}$, and subsequently stimulated by $30 \mathrm{ng} / \mathrm{ml}$ of TNF- $\alpha$ or vehicle for $10 \mathrm{~min}$. The cell extracts were subjected to SDS-PAGE with subsequent western blot analysis with antibodies against phospho-specific p70 S6 kinase or p70 S6 kinase. The histogram shows quantitative representation of the levels of TNF- $\alpha$-induced phosphorylation obtained from a laser densitometric analysis of three independent experiments. Each value represents the mean \pm standard error of the mean of triplicate determinations. ${ }^{\text {}} \mathrm{P}<0.05$ compared to the value of the control; N.S. designates no significant differences between the indicated pairs.

Effects of EGCG or CGA on the TNF- $\alpha$-induced phosphorylation of p70 S6 kinase in MC3T3-E1 cells. Our previous study reported that p70 S6 kinase has a suppressive role in the TNF- $\alpha$-stimulated interleukin- 6 synthesis in osteoblast-like MC3T3-E1 cells (19). Therefore, to clarify whether the effects of EGCG or CGA on the TNF- $\alpha$-stimulated interleukin- 6

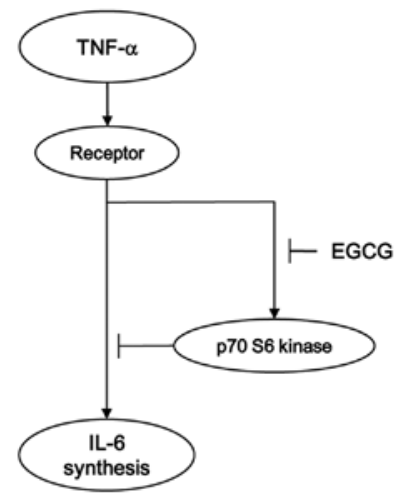

Figure 6. Diagram of the potential mechanism for the amplification by (-)-epigallocatechin gallate (EGCG) of the tumor necrosis factor- $\alpha$ $(\mathrm{TNF}-\alpha)$-induced interleukin-6 synthesis in MC3T3-E1 cells. EGCG enhances the TNF- $\alpha$-stimulated interleukin- 6 synthesis via the suppression of p70 S6 kinase in osteoblast-like MC3T3-E1 cells.

synthesis are associated with the activation of p70 S6 kinase in MC3T3-E1 cells, the effects of EGCG or CGA on the TNF- $\alpha$-induced phosphorylation of p70 S6 kinase were further examined. EGCG significantly suppressed the TNF- $\alpha$-induced phosphorylation of p70 S6 kinase in a dose-dependent manner between 10 and $100 \mu \mathrm{M}$ (Fig. 4). By contrast, CGA did not affect the TNF- $\alpha$-induced phosphorylation of p70 S6 kinase between 10 and $50 \mu \mathrm{M}$ (Fig. 5).

\section{Discussion}

In the present study, EGCG, a main flavonoid in green tea, and CGA, a bioactive compound in coffee, were demonstrated to enhance the TNF- $\alpha$-stimulated interleukin- 6 release in osteoblast-like MC3T3-E1 cells. Additionally, the expression levels of interleukin- 6 mRNA induced by TNF- $\alpha$ were amplified by EGCG, as well as CGA. Thus, it appears that the enhancing effects of EGCG and CGA on the TNF- $\alpha$-stimulated interleukin- 6 release are mediated through transcriptional levels in MC3T3-E1 cells. Taking the present findings into account, it is most likely that EGCG and CGA in beverages upregulate TNF- $\alpha$-stimulated synthesis of interleukin- 6 in osteoblast-like MC3T3-E1 cells.

Regarding the intracellular signaling of TNF- $\alpha$-stimulated interleukin-6 synthesis in osteoblasts, our previous study reported that TNF- $\alpha$ stimulates the activation of p70 S6 kinase in osteoblast-like MC3T3-E1 cells, resulting in the limitation of the TNF- $\alpha$-stimulated interleukin-6 synthesis (19). Based on these results, the precise mechanism behind the enhancement by EGCG and CGA of the TNF- $\alpha$-stimulated interleukin- 6 synthesis in MC3T3-E1 cells was investigated. EGCG markedly suppressed the TNF- $\alpha$-stimulated phosphorylation of the p70 S6 kinase. However, CGA failed to affect the phosphorylation of p70 S6 kinase. Therefore, it is most likely that EGCG strengthens the TNF- $\alpha$-stimulated interleukin- 6 synthesis through the inhibition of p70 S6 kinase in osteoblast-like MC3T3-E1 cells. By contrast, it appears unlikely that the enhancing effect of CGA on the TNF- $\alpha$-induced interleukin- 6 synthesis is mediated through $p 70$ S6 kinase. In our previous studies, we have reported that p70 S6 kinase negatively regulates the interleukin- 6 synthesis stimulated by platelet-derived growth factor (PDGF), a bone remodeling 
modulator in osteoblast-like MC3T3-E1 cells (25). Additionally, our previous study showed that EGCG reduces the interleukin-6 synthesis by platelet-derived growth factor without affecting the p70 S6 kinase activation (26). It is generally recognized that platelet-derived growth factor receptor has an intrinsic protein tyrosine kinase activity, whereas TNF- $\alpha$ receptor belongs to the cytokine receptor superfamily, and that the signal transduction mechanisms are quite different from each other $(12,27)$. Thus, it appears likely that different and rather opposite effects of EGCG on p70 S6 kinase activation and interleukin-6 synthesis induced by TNF- $\alpha$ or PDGF-BB in osteoblast-like MC3T3-E1 cells are due to the difference between each receptor-mediated intracellular signaling. Further investigations are required to clarify the details underlying the effects of EGCG and CGA on the interleukin- 6 synthesis in osteoblasts. The potential mechanism of EGCG in the TNF- $\alpha$-stimulated interleukin- 6 synthesis in osteoblasts is summarized in Fig. 6.

Polyphenolic compounds in beverages, including green tea and coffee, have beneficial properties for human health. With regard to bone metabolism, accumulating evidence indicates that green tea consumption contributes bone formation, improves bone mineral density and decreases the risk of fracture (7). Additionally, it is currently known that coffee consumption reduces the risk of osteoporosis and osteoporotic fracture in elderly people (28). In the present study, EGCG and CGA amplified the TNF- $\alpha$-stimulated interleukin- 6 synthesis in osteoblast-like MC3T3-E1 cells. In bone metabolism, interleukin- 6 has long been recognized to act as a powerful bone resorptive agent and promotes osteoclast formation (29). However, interleukin- 6 is currently considered as an osteotropic factor under the condition of increased bone turnover and induces bone formation (17). Bone resorption is the first step of bone remodeling, and subsequently bone formation is initiated (4). To obtain the quantity and quality of bone, adequate bone remodeling processed by osteoclasts and osteoblasts is essential. With regard to bone metabolism as a whole, it is possible that interleukin-6 functions as a bone remodeling mediator. In addition, it has been reported that interleukin- 6 has a crucial role in the initiation of bone formation in an early stage of bone fracture repair (16). Therefore, the present findings that EGCG and CGA enhance the TNF- $\alpha$-stimulated interleukin- 6 synthesis in osteoblasts provide a new insight in fracture prevention in elderly people. Further investigations are required to elucidate the exact roles of EGCG and CGA in bone metabolism.

In conclusion, the present results strongly suggest that EGCG and CGA enhance the TNF- $\alpha$-stimulated interleukin-6 synthesis in osteoblasts and that the enhancement by EGCG, but not CGA, is exerted via inhibiting p70 S6 kinase.

\section{Acknowledgements}

The authors are extremely grateful to Mrs. Yumiko Kurokawa for her skillful technical assistance. The present study was supported in part by a Grant-in-Aid for Scientific Research (grant no. 19591042) from the Ministry of Education, a Grant-in-Aid for Scientific Research (grant no. H25-Aging-General-004) from the Ministry of Health, Labour and Welfare, and the Research Funding for Longevity Sciences (grant no. 25-4, 26-12) from the National Center for Geriatrics and Gerontology, Japan.

\section{References}

1. George SE, Ramalakshmi K and Mohan Rao LJ: A perception on health benefits of coffee. Crit Rev Food Sci Nutr 48: 464-486, 2008.

2. Thielecke F and Boschmann M: The potential role of green tea catechins in the prevention of the metabolic syndrome - a review. Phytochemistry 70: 11-24, 2009.

3. Shimizu M, Adachi S, Masuda M, Kozawa O and Moriwaki H: Cancer chemoprevention with green tea catechins by targeting receptor tyrosine kinases. Mol Nutr Food Res 55: 832-843, 2011.

4. Karsenty G and Wagner EF: Reaching a genetic and molecular understanding of skeletal development. Dev Cell 2: 389-406, 2002.

5. Zuo C, Huang Y, Bajis R, Sahih M, Li YP, Dai K and Zhang X: Osteoblastogenesis regulation signals in bone remodeling. Osteoporos Int 23: 1653-1663, 2012.

6. Hadjidakis DJ and Androulakis II: Bone remodeling. Ann NY Acad Sci 1092: 385-396, 2006.

7. Shen CL, Yeh JK, Cao JJ and Wang JS: Green tea and bone metabolism. Nutr Res 29: 437-456, 2009.

8. Singh R, Akhtar N and Haqqi TM: Green tea polyphenol epigallocatechin-3-gallate: Inflammation and arthritis. [corrected]. Life Sci 86: 907-918, 2010.

9. Folwarczna J, Pytlik M, Zych M, Cegieła U, Nowinska B, Kaczmarczyk-Sedlak I, Sliwinski L, Trzeciak $\mathrm{H}$ and Trzeciak HI: Effects of caffeic and chlorogenic acids on the rat skeletal system. Eur Rev Med Pharmacol Sci 19: 682-693, 2015.

10. Kwak SC, Lee C, Kim JY, Oh HM, So HS, Lee MS, Rho MC and Oh J: Chlorogenic acid inhibits osteoclast differentiation and bone resorption by down-regulation of receptor activator of nuclear factor kappa-B ligand-induced nuclear factor of activated T cells c1 expression. Biol Pharm Bull 36: 1779-1786, 2013.

11. Kwan Tat S, Padrines M, Théoleyre S, Heymann D and Fortun Y: IL-6, RANKL, TNF-alpha/IL-1: Interrelations in bone resorption pathophysiology. Cytokine Growth Factor Rev 15: 49-60, 2004.

12. Zou W, Hakim I, Tschoep K, Endres S and Bar-Shavit Z: Tumor necrosis factor-alpha mediates RANK ligand stimulation of osteoclast differentiation by an autocrine mechanism. J Cell Biochem 83: 70-83, 2001.

13. Ishimi Y, Miyaura C, Jin CH, Akatsu T, Abe E, Nakamura $\mathrm{Y}$, Yamaguchi A, Yoshiki S, Matsuda T, Hirano T, et al: IL-6 is produced by osteoblasts and induces bone resorption. J Immunol 145: 3297-3303, 1990.

14. Akira S, Taga T and Kishimoto T: Interleukin-6 in biology and medicine. Adv Immunol 54: 1-78, 1993.

15. Heymann D and Rousselle AV: gp130 Cytokine family and bone cells. Cytokine 12: 1455-1468, 2000.

16. Fazzalari NL: Bone fracture and bone fracture repair. Osteoporos Int 22: 2003-2006, 2011.

17. Franchimont N, Wertz S and Malaise M: Interleukin-6: An osteotropic factor influencing bone formation? Bone 37: 601-606, 2005.

18. Kozawa O, Suzuki A, Kaida T, Tokuda $\mathrm{H}$ and Uematsu T: Tumor necrosis factor- $\alpha$ autoregulates interleukin- 6 synthesis via activation of protein kinase $C$. Function of sphingosine 1-phosphate and phosphatidylcholine-specific phospholipase C. J Biol Chem 272: 25099-25104, 1997.

19. Minamitani C, Tokuda H, Adachi S, Matsushima-Nishiwaki R, Yamauchi J, Kato K, Natsume H, Mizutani J, Kozawa O and Otsuka T: p70 S6 kinase limits tumor necrosis factor-alpha-induced interleukin-6 synthesis in osteoblast-like cells. Mol Cell Endocrinol 315: 195-200, 2010.

20. Sudo H, Kodama HA, Amagai Y, Yamamoto S and Kasai S: In vitro differentiation and calcification in a new clonal osteogenic cell line derived from newborn mouse calvaria. J Cell Biol 96: 191-198, 1983.

21. Kozawa O, Tokuda H, Miwa M, Kotoyori J and Oiso Y: Cross-talk regulation between cyclic AMP production and phosphoinositide hydrolysis induced by prostaglandin E2 in osteoblast-like cells. Exp Cell Res 198: 130-134, 1992.

22. Simpson DA, Feeney S, Boyle C and Stitt AW: Retinal VEGF mRNA measured by SYBR green I fluorescence: A versatile approach to quantitative PCR. Mol Vis 6: 178-183, 2000.

23. Laemmli UK: Cleavage of structural proteins during the assembly of the head of bacteriophage T4. Nature 227: 680-685, 1970 . 
24. Kato $\mathrm{K}$, Ito $\mathrm{H}$, Hasegawa $\mathrm{K}$, Inaguma $\mathrm{Y}$, Kozawa $\mathrm{O}$ and Asano T: Modulation of the stress-induced synthesis of hsp27 and alpha B-crystallin by cyclic AMP in C6 rat glioma cells. J Neurochem 66: 946-950, 1996.

25. Takai S, Tokuda H, Hanai $Y$ and Kozawa O: Limitation by $p 70$ S6 kinase of PDGF-BB-induced IL-6 synthesis in osteoblast-like MC3T3-E1 cells. Metabolism 56: 476-483, 2007.

26. Takai S, Matsushima-Nishiwaki R, Adachi S, Natsume H, Minamitani C, Mizutani J, Otsuka T, Tokuda H and Kozawa O: (-)-Epigallocatechin gallate reduces platelet-derived growth factor-BB-stimulated interleukin-6 synthesis in osteoblasts: Suppression of SAPK/JNK. Mediators Inflamm 2008: 291808, 2008.
27. Heldin $\mathrm{CH}$ and Westermark B: Mechanism of action and in vivo role of platelet-derived growth factor. Physiol Rev 79: 1283-1316, 1999.

28. Higdon JV and Frei B: Coffee and health: A review of recent human research. Crit Rev Food Sci Nutr 46: 101-123, 2006.

29. Blair HC and Athanasou NA: Recent advances in osteoclast biology and pathological bone resorption. Histol Histopathol 19: 189-199, 2004 